\title{
Human Work Interaction Design for e-Government and Public Information Systems
}

\author{
Dinesh Katre ${ }^{1}$, Pedro Campos ${ }^{2}$, Torkil Clemmensen ${ }^{3}$, \\ Rikke Orngreen ${ }^{4}$, and Annelise Mark Pejtersen ${ }^{5}$ \\ ${ }^{1}$ Human-Centred Design \& Computing, C-DAC Pune, India \\ ${ }^{2}$ Madeira Interactive Technologies Inst., Universidade da Madeira, Portugal \\ ${ }^{3}$ Department of Informatics, Copenhagen Business School, Denmark \\ ${ }^{4}$ Media and ICT in a Learning Perspective, Aarhus University, Denmark \\ ${ }^{5}$ Center of Cognitive Systems Engineering, Denmark \\ dinesh@cdac.in, pedro.campos.pt@gmail.com, tc.inf@cbs.dk, \\ RIOR@dpu.dk, ampcse@mail.dk
}

\begin{abstract}
Varied backgrounds of users, heterogeneous delivery media and diverse socio-cultural and organizational contexts pose new challenges of human work interaction design in the field of e-government and public information systems. The workshop will consolidate the empirical case studies of how human work analysis and interaction design has benefited in enhancing the user experience of e-government and public information systems and a set of effective methods, techniques and theories for this purpose. Selected research papers from the workshop will be published in the International Journal of Public Information Systems (IJPIS), Sweden.
\end{abstract}

Keywords: Interaction design, human work analysis, empirical case studies, egovernment, public information systems.

\section{Workshop Theme}

This proposal is for the one day workshop during INTERACT 2011 to be organized by the members of WG 13.6 Human Work Interaction Design (authors of this proposal). We propose to involve the community of WG 8.5 Information Systems in Public Administration.

The complex interplay and information exchanges between the models of Government to Government, Government to Business and Government to Citizen pose different kind of challenges while designing the e-government systems. Human work analysis is very critical in public information systems design as the procedures, working styles, organizational contexts are different in various public sector organizations. Interaction design of e-government system and public information systems has to simultaneously address the user experience requirements of diverse users such as people from varied educational and professional backgrounds, senior citizens, physically disabled, illiterate and people with different languages and cultural preferences. The combination of Human Work analysis and Interaction Design in user interface design for e-government systems has to adopt itself to diverse delivery media such as web, desktop, touch screen kiosks and mobile devices. 
We would like to invite position papers on the theme of the workshop following (but not excluded to) methodological approaches and domains such as -

- Human work analysis and interaction design case studies in egovernment and public information systems

- The influence of socio-economical, political and cultural context on the design of public information systems

- Social networks and collaborative user interfaces for policy crowdsourcing

- Government-centric versus citizen-centric design approaches

- User interface design for diverse delivery media for e-government services such as web, desktop, touch screen kiosk and mobile devices

- Designing for diverse users, Every-citizen interface design, Mass personalization

- Democratic design for e-government

- HCI challenges in bridging the digital divide through e-government

- Usability evaluation methods for e-government

- User experience design for e-government

\subsection{Intended Audience}

The theme of this workshop involves many disciplines across academic boundaries and hence a diverse audience can submit papers and attend the workshop. Obviously, people attending INTERACT 2011 and Participants of IFIP HWID WG 13.6, but also practitioners and researchers, who attend only this workshop, because they have a specific interest in the proposed themes. For example, researchers and practitioners in:

- e-government and public information systems

- Organizational engineering and work analysis

- Interaction design

- E-government policy makers

- Public information system design / development

- HCI, Usability and UX practice

This INTERACT workshop takes place in Portugal, and we encourage Portuguese researchers and practitioners to submit papers and to participate.

\subsection{Publication of Workshop Papers}

We have already formed an international programme committee for reviewing the research papers of this workshop. International Journal of Public Information Systems (IJPIS), Sweden has agreed to publish a special issue from the proceedings of this workshop. 